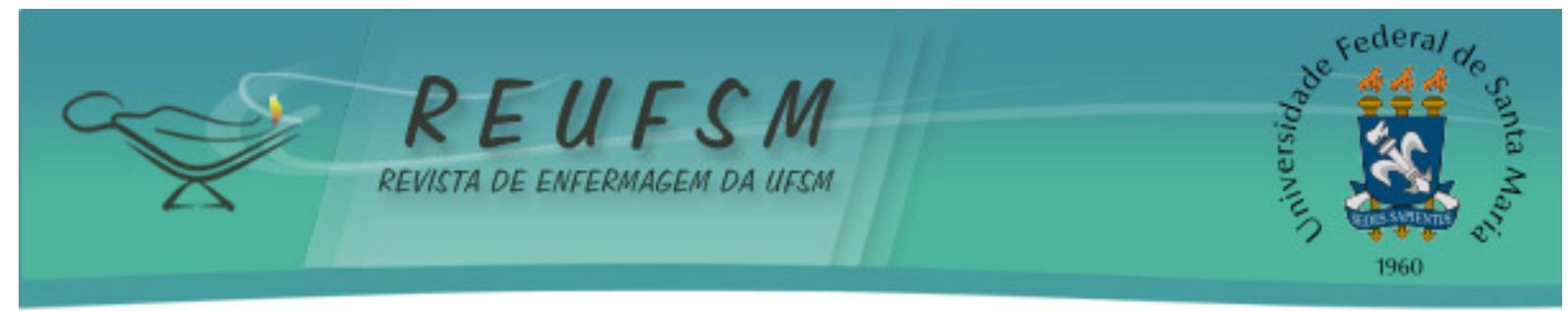

ARTIGO ORIGINAL

\title{
PERMANECER SUS: A (RE) FORMAÇÃO EM SAÚDE SOB A PERSPECTIVA DO ACOLHIMENTO E DA HUMANIZAÇÃO
}

\section{PERMANECER SUS: THE (RE) TRAINING IN HEALTH THROUGH THE PERSPECTIVE USER EMBRACEMENT AND HUMANIZATION}

\section{PERMANECER SUS: A (RE) FORMACIÓN EN SALUD BAJO LA PERSPECTIVA DE ACOGIMENTO Y HUMANIZACION}

Wilton Nascimento Figueredo ${ }^{1}$

David Ramos da Silva Rios ${ }^{2}$

Priscyla Santana Ferreira Teles ${ }^{3}$

Talita Karen Santos Barros Magalhães ${ }^{4}$

Renata Meira Véras ${ }^{5}$

Doi: 10.5902/2179769213593

RESUMO: Objetivo: analisar a percepção dos estudantes integrantes do programa Permanecer SUS da Secretaria de Saúde do Estado da Bahia, a partir da Política Nacional de Humanização. Método: estudo qualitativo do tipo pesquisa de campo com abordagem da Etnografia Institucional. Foram realizadas observações participantes e entrevistas semiestruturadas com 10 acadêmicos da área da saúde. Resultados: os dados analisados mostram que o programa apresenta influências positivas para a formação universitária dos participantes. Um dos maiores benefícios apontados é de que há maior sensibilização acerca dos princípios do acolhimento e humanização, e consequentemente uma melhor compreensão acerca do sistema de saúde pública do Brasil. Conclusão: por meio do discurso dos sujeitos emergiram aspectos da importância do programa para a formação profissional e o reconhecimento da vulnerabilidade de uma assistência integral e humanizada nos serviços de saúde.

Descritores: Universidades; Educação em saúde; Acolhimento; Humanização da assistência.

ABSTRACT: Aim: to analyze the perception of students members of Permanecer SUS program of the Health Secretariat in Bahia, from the National Policy of Humanization. Method: qualitative study of field research with Institutional Ethnography approach. Participant observation and semi-structured interviews were conducted with 10 academics in the health field. Results: the data shows that the program has a positive influence for the participant's academic education. One of the biggest benefits appointed is that there is greater awareness about the principles user embracement and humanization, and consequently a better understanding of the public health system in Brazil. Conclusion:

\footnotetext{
1 Enfermeiro. Mestrando no Programa de Pós-Graduação em Estudos Interdisciplinares sobre a Universidade (PPGEISU). Universidade Federal da Bahia (UFBA). Salvador, Bahia, Brasil. E-mail: enfer.willfigueredo@gmail.com

${ }^{2}$ Bacharel em Saúde e Estudante. Graduando em Medicina. Universidade Federal da Bahia. Salvador, Bahia, Brasil. E-mail: david-rios@hotmail.com

${ }^{3}$ Bacharel em Saúde e Estudante. Graduanda em Enfermagem. Universidade Federal da Bahia. Salvador, Bahia, Brasil. E-mail: teles.priscyla@hotmail.com

${ }^{4}$ Enfermeira e Bacharel em Saúde. Graduanda em Farmácia. Universidade Federal da Bahia. Salvador, Bahia, Brasil. E-mail: talitaksb@hotmail.com

${ }^{5}$ Doutora em Psicologia Social pela Universidade Federal do Rio Grande do Norte, professora do Instituto de Artes, Humanidades e Ciências Milton Santos (IHAC-UFBA), docente permanente e coordenadora do Programa de Pós-Graduação em Estudos Interdisciplinares sobre a Universidade (PPGEISU). Universidade Federal da Bahia. Salvador, Bahia, Brasil. E-mail: renata.veras@ufba.br
} 


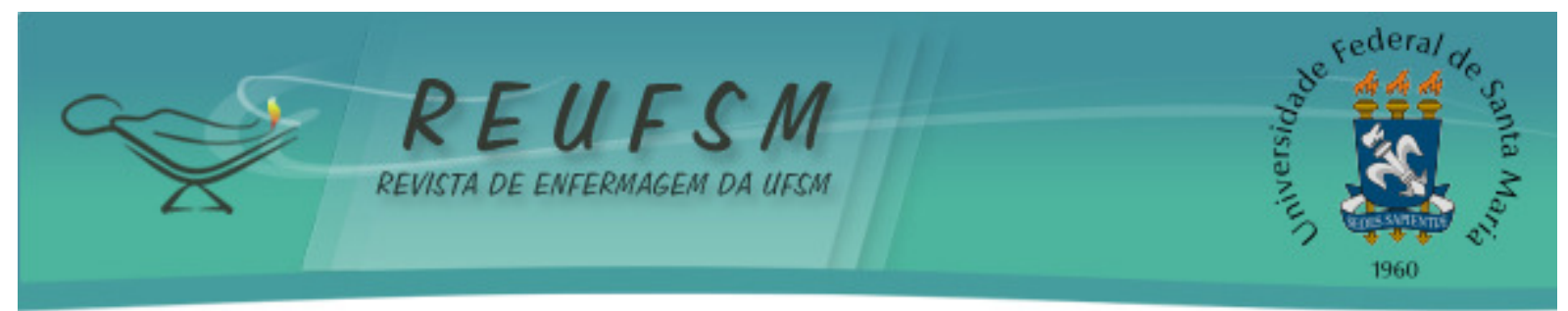

according to the subjects' speech, aspects on the importance of the program for professional formation and recognition of the vulnerability of an integral and humanized care in health services emerged.

Descriptors: Universities; Health education; User embracement; Humanization of assistance.

RESUMEN: Objetivo: analizar las percepciones de los estudiantes del programa Permanecer SUS de la Secretaría de Salud del Estado de Bahía, de la Política Nacional de Humanización. Método: estudio cualitativo e investigativo con enfoque de Etnografía Institucional. Entrevistas de observación participante y semi-estructuradas con 10 académicas de la salud. Resultados: los datos analizados muestran que el programa tiene una influencia positiva para la educación universitaria de los participantes. Uno de los mayores beneficios es la mayor conciencia acerca de los principios de acogimiento y humanización, y por lo tanto una mejor comprensión del sistema de salud pública en Brasil. Conclusión: mediante el discurso de los temas surgieron aspectos como la importancia del programa para la formación profesional y el reconocimiento de la vulnerabilidad de una atención integral y humanizada en los servicios de salud.

Descriptores: Universidades; Educación en salud; Acogimiento; Humanización en la atención.

\section{INTRODUÇÃO}

A formação profissional superior em saúde se constitui objeto de discussão nas conferências nacionais de saúde e de recursos humanos há mais de duas décadas, compondo textos referentes à legislação do Sistema Único de Saúde (SUS) e suas bases normativas. ${ }^{1}$

No entanto, apesar das discussões, essa mesma formação ainda se encontra fortemente orientada pelo modelo flexneriano..$^{2-3} 0$ modelo flexneriano, ou mais comumente conhecido como o paradigma biomédico, foi proposto por Abraham Flexner, em 1910 nos Estados Unidos e difundiu-se, erroneamente, pelo mundo numa perspectiva biologicista da doença, negando a determinação social da saúde, reduzindo o conhecimento em disciplinas e uma formação clínica voltada para a cura de doenças e da alta tecnologia encontrada nos hospitais. ${ }^{2}$

Assim, a proposta de Flexner, contrapondo os modelos de ensino e de prática com o contexto democrático brasileiro, passa a desconsiderar as reais necessidades de atenção à saúde da população, inviabilizando o desenvolvimento e fortalecimento do SUS. ${ }^{2}$

$\mathrm{Na}$ área da educação, é importante destacar que estudos ${ }^{4-7}$ mais recentes vêm afirmando que o novo perfil do profissional de saúde depende, majoritariamente, da instituição formadora, que deverá reestruturar os currículos e processos de ensino aprendizagem, com base na Lei de Diretrizes e Bases da Educação (LDB) nº 9.394 de 20 de dezembro de $1996^{8}$ e nas Diretrizes Curriculares Nacionais (DCN). Dessa forma, poderá estimular um processo de formação crítico, reflexivo, dinâmico e capaz de interpretar e intervir nas demandas e necessidades contemporâneas de saúde, seja pública ou privada, mediante um olhar humanizado e acolhedor.

Resultante da aproximação estratégica entre o Ministério da Saúde (MS) e Ministério da Educação (MEC), em 2005, surgiu o Programa de Reorientação Profissional em Saúde (Pró-Saúde). ${ }^{1,8}$

O Pró-Saúde, então incluído na Política Nacional de Educação na Saúde ${ }^{1}$, foi o precursor para que novos projetos e modalidades fossem criados nas outras esferas da gestão (Estados e 


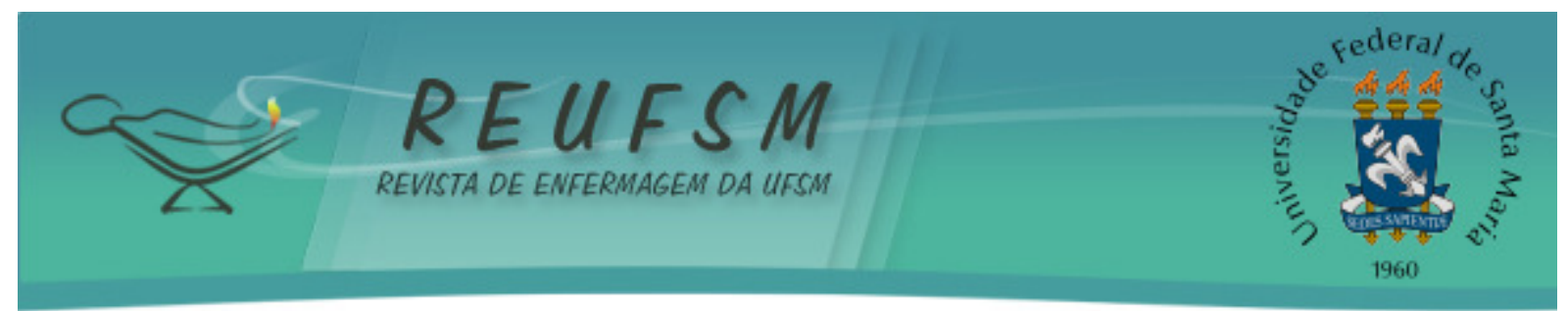

Municípios), possibilitando, por meio de seu objetivo, a indução de mudanças nas graduações, a articulação entre universidades e serviços de saúde, em prol do SUS.

A educação em saúde concebida como as práticas da educação no campo da saúde, orientada pelo estudo, pela pesquisa e pela inclusão social, se torna primordial para a formação técnica dos profissionais, assim como na compreensão do papel do homem na sociedade. $^{8}$

No caso específico da Bahia, a Secretaria da Saúde do Estado (SESAB), por meio da Diretoria de Gestão da Educação e Trabalho em Saúde (DGTES), instituiu em 2008 o programa Permanecer SUS, embasado no princípio do acolhimento, proposto pela Política Nacional de Humanização (PNH). ${ }^{9}$

0 acolhimento se configura como uma questão ética, que visa o compromisso às necessidades dos cidadãos reconhecendo-os como parceiros no cuidado em saúde. ${ }^{9}$

Assim, o objetivo do programa é o de promover a vivência dos futuros profissionais na realidade da organização dos serviços públicos de saúde, mediante a prática do acolhimento, integralidade do cuidado, assentando-se nos valores de autonomia e no conceito de humanização. ${ }^{9}$ A humanização pode ser definida como o reconhecimento do protagonismo dos sujeitos (usuários, trabalhadores e gestores), de corresponsabilidade entre eles, de solidariedade dos vínculos, dos direitos e da participação coletiva no processo de gestão. ${ }^{5}$

Consequentemente, as ações desenvolvidas no Permanecer SUS pretendem direcionar a integração ensino-serviço, por meio de experiências transdisciplinares. A transdisciplinaridade compreende a realidade como multidimensional e possibilita a "inclusão do terceiro excluído" ao reassumi-los como seres sociais na sua integralidade. ${ }^{10: 133}$

Do ponto de vista estrutural e normativo, por meio da cooperação entre a SESAB e três instituições de ensino superior da Bahia (Universidade Federal da Bahia, Universidade Católica do Salvador, Universidade do Estado da Bahia), os alunos dos cursos de saúde, entre eles, Bacharelado Interdisciplinar, Enfermagem, Fonoaudiologia, Medicina, Serviço Social e Psicologia, assinam contrato como estagiários por seis meses, prorrogável ou não por igual período, integrando equipes multidisciplinares nas unidades de urgência de quatro hospitais públicos da região metropolitana de Salvador, conveniados ao Permanecer SUS.

Acredita-se que a realização de um estudo que possa ao mesmo tempo avaliar um projeto que tenta articular os campos da saúde e educação e aproximar as contribuições universitárias ao espaço direto da construção das políticas públicas de saúde constitui-se em oportunidade relevante. Para esse tipo de estudo, é indispensável investigar a visão dos acadêmicos que participam desse projeto para responder à questão: "Qual a percepção dos estudantes participantes acerca da contribuição do programa Permanecer SUS para a sua formação profissional?”

0 presente estudo, portanto, objetiva analisar a percepção dos estudantes integrantes do programa Permanecer SUS da Secretaria de Saúde do Estado da Bahia, a partir da Política Nacional de Humanização.

\section{MÉTODO}

Estudo com abordagem qualitativa, do tipo pesquisa de campo, sob a perspectiva da Etnografia Institucional (El).

A El, por meio de um mergulho nas atividades cotidianas das relações institucionais, se apresenta como uma abordagem que busca conhecer como vem sendo construídas e organizadas as relações sociais nas instituições, bem como qual o sentido que as pessoas dão para o que vivenciam nas diferentes situações. ${ }^{11}$ 


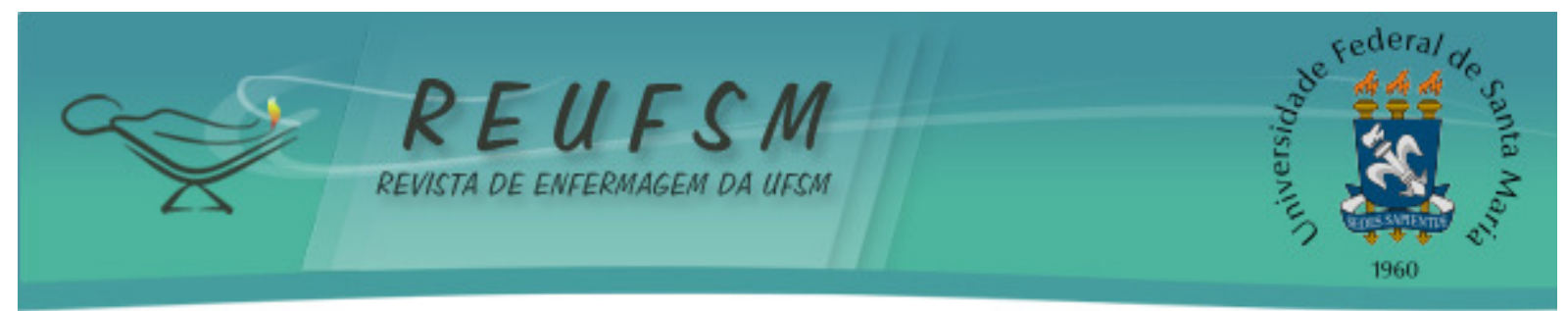

$\mathrm{Na}$ coleta de dados utilizou-se a entrevista, juntamente com a observação participante, realizadas no período compreendido entre maio e junho de 2013, em variados dias úteis da semana, no setor de emergência de um, dos quatro, hospitais gerais e público participantes do Programa Permanecer SUS, localizado na cidade de Salvador, Bahia.

Por se tratar da fase inicial e de teste da pesquisa, o referido hospital foi o primeiro a ser escolhido por ser de ensino, de grande porte, assistencial em diversas especialidades médicas e diariamente receber inúmeros atendimentos de urgência e emergência.

Os critérios de inclusão dos sujeitos foram: ser estagiário/bolsista remunerado do Permanecer SUS, maiores de 18 anos e estar alocado no setor de emergência adulta. Para homogeneizar as discussões foram excluídos os estagiários da emergência pediátrica, uma vez que esses setores possuem dinâmica diferenciada de atendimento.

Como a normativa do programa é a de alocar 5 estudantes por setor e turno, foram convidados todos os 10 integrantes e não se obteve recusas.

A coleta de dados iniciou-se em maio de 2013 com a observação participante que durou em média 80 horas, compreendendo 40 períodos de observação. Cada período teve duração em torno de 2 horas. Este período compreendeu a visita de todo o setor de emergência do hospital, conhecer as atividades dos estagiários, participar como ouvinte dos atendimentos prestados, ao mesmo tempo em que se ouvia as queixas dos usuários e as indagações dos profissionais de saúde eram registrados no diário de campo.

As entrevistas só iniciaram no mês subsequente à observação. Escolheu-se a entrevista semiestruturada, previamente construída por questões guias. Estas, por sua vez, foram definidas em quatro partes: a primeira abordava dados sociodemográficos, a segunda concepções sobre acolhimento e humanização dos estagiários do Permanecer SUS, a terceira contribuição do programa para a formação curricular do estudante, a quarta e última dificuldades para desenvolver o acolhimento e humanização.

Cada entrevista durou, aproximadamente, entre 20 a 40 minutos. Foram gravadas em aparelho eletrônico específico para captar a voz dos indivíduos, automaticamente armazenadas e posteriormente transcritas fidedignamente no programa Microsoft Word 2013.

O sigilo e o anonimato foram mantidos, assim se preservou a identidade da instituição hospitalar e dos entrevistados. Estes últimos foram identificados como "Estudante" acrescido do curso de saúde pertencente.

Após toda a coleta deu-se início à análise dos dados. Essa foi realizada em três passos. 0 primeiro passo foi realizar a leitura exaustiva do material coletado. 0 segundo foi destacar nas falas as temáticas em comum, fragmentando os discursos. Em seguida esses fragmentos foram agrupados em categorias, passando pela análise interpretativa com a finalidade de significar as falas dos acadêmicos.

A análise de discurso foi a estratégia utilizada para analisar o discurso dos entrevistados. Partindo dos conceitos estruturantes da PNH, como o acolhimento e humanização, buscou-se compreender, por meio das palavras dos entrevistados, o sentido que elas exercem no processo de significação do estágio, portanto na interpretação dos objetivos do programa Permanecer SUS. ${ }^{12}$

Os aspectos éticos foram preservados nesta pesquisa e em acordo com a resolução $n^{\circ} 466 / 2012$ do Conselho Nacional de Saúde ${ }^{13}$, obtendo, portanto, aprovação do Comitê de Ética e Pesquisa do Instituto de Saúde Coletiva da Bahia (ISC-BA), registrada sobre o parecer $n^{\circ}$ 002-11/CEP - ISC.

\section{RESULTADOS E DISCUSSÃO}

Os 10 acadêmicos participantes da pesquisa tinham entre 18 e 23 anos de idade, estavam entre o terceiro e quarto semestre do curso de saúde, igualmente divididos entre 


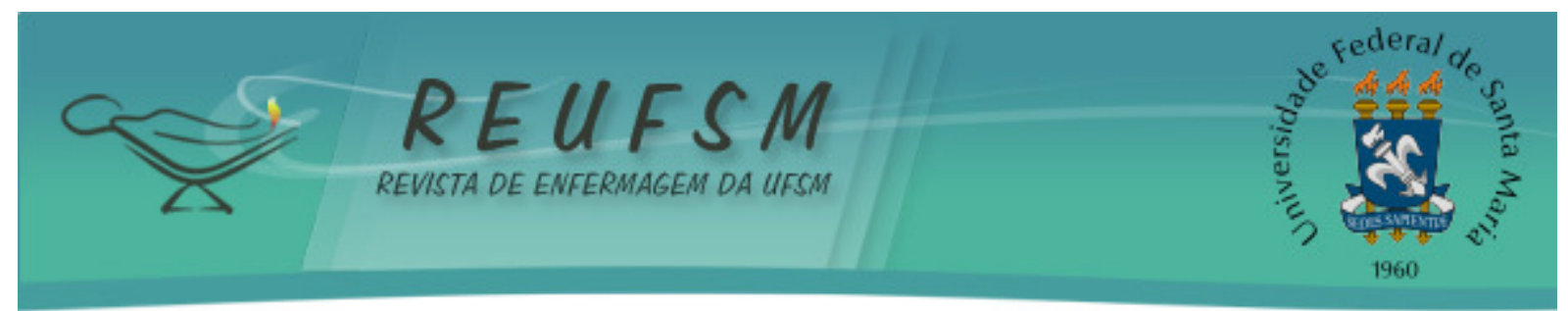

o turno matutino e vespertino. Três eram do curso de Enfermagem, três do curso Bacharelado Interdisciplinar em Saúde, dois do curso de Psicologia e os outros dois do curso de Medicina.

As categorias analíticas foram desenvolvidas de acordo com a proximidade das falas dos entrevistados com os propósitos do "objeto simbólico"12:26 do estudo, neste caso o Permanecer SUS e, consequentemente, da Política Nacional de Humanização. Assim, as categorias equipe multidisciplinar e experiências interdisciplinares, relações interpessoais e clínica ampliada (humanização e acolhimento), foram adotadas na tentativa de explicitar a compreensão da "significância do objeto simbólico para e por os sujeitos"12:26 da pesquisa.

\section{Equipe multidisciplinar e experiências interdisciplinares}

Ressalta-se que na área da saúde é praticamente impossível que apenas um ou dois profissionais exerçam completamente as ações de saúde, por isso a integração dos mais diversos segmentos da saúde se faz necessária para o alcance da qualidade, eficiência dos serviços prestados e para a integralidade das ações dos serviços de saúde. ${ }^{14-15}$

Compreende-se por integralidade a consciência de que o sujeito, o usuário de saúde, é um ser que se insere, de forma total, mas não necessariamente em sua plenitude, na sociedade e nas relações sociais, sejam elas históricas, políticas ou familiares. ${ }^{16}$

Para a realização de uma prática que atenda a integralidade, dentre outras necessidades, é necessário exercitar efetivamente o trabalho em equipe. Por isso, estimula-se o desenvolvimento de estratégias de aprendizagem, a exemplo de vivências, estágios, discussões, na formação acadêmica que favoreçam a comunicação.

É possível destacar nos dois depoimentos a seguir que um dos objetivos do programa Permanecer SUS, é a formação de equipes multidisciplinares, exercitando experiências transdisciplinares, ou seja a interdisciplinaridade acontecendo de acordo com o seu conceito, que é o distanciamento da disciplinaridade, do olhar centralizado apenas por um único profissional de saúde e a perspectiva dialógica do sujeito com o objeto..$^{10,17}$

A gente tinha um grupo no Permanecer SUS e fazíamos um trabalho em equipe, ajudando uns aos outros. Éramos nós do Bacharelado, Medicina, Fonoaudiologia, Enfermagem [...]. (Estudante do Bacharelado Interdisciplinar em Saúde)

Além de trabalhar com o acolhimento, com a proposta [...] do SUS a gente pode perceber o quanto todas as áreas do saber juntas podem contribuir, ao dialogar entre si [...]. (Estudante de Psicologia)

Em contrapartida, os discursos de outros estudantes apontaram a falta de preparo dos demais profissionais para o trabalho em equipe, do não entrosamento, o que geralmente dificultava as ações desenvolvidas. Consequentemente, compreende-se que a interdisciplinaridade é um grande desafio nos serviços multiprofissionais. ${ }^{18}$

É preciso trabalhar em equipe, é preciso a colaboração dos outros profissionais e era isso o que mais dificultava [...] o problema principal eram os profissionais da unidade que não sabiam trabalhar em equipe, faziam as coisas sem se comunicar. (Estudante de Enfermagem) 


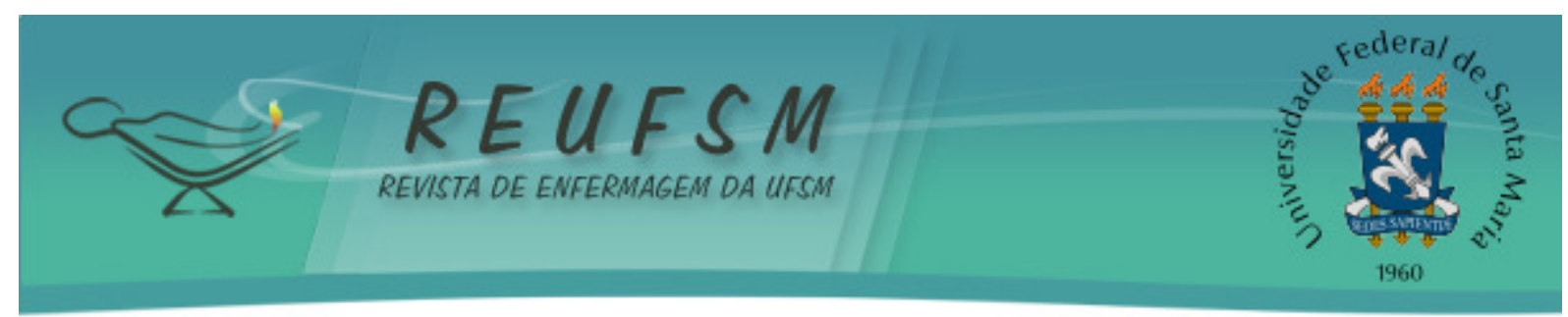

Olha, sem dúvida nenhuma, a maior dificuldade é o trabalho multiprofissional, o interdisciplinar. De saber trabalhar em conjunto [...]. (Estudante de Psicologia)

Nota-se, portanto, que os estudantes consideram a inclusão de abordagens que priorizem o trabalho em equipe é relevante para as ações no SUS, na perspectiva de se alcançar a interdisciplinaridade. No entanto, acreditam que as demandas para esse tipo de prática não podem estar apenas relacionadas a um conceito de ensino nas universidades, mas prioritariamente atreladas à sociedade e aos problemas da organização do trabalho, visto a necessidade de conduzir ações, serviços e sistemas por meio de rede e solidariedade intersetorial. ${ }^{9}$

\section{Relações interpessoais}

Relações interpessoais podem ser compreendidas como diversas facetas de um processo comunicacional, de autoconhecimento, que intervenha como instrumento das relações de humanização entre os envolvidos no processo de saúde-doença. ${ }^{19}$

A temática humanização está permeada de diversos fatores que vão desde a operacionalização de um projeto político de saúde calçado em valores como cidadania, compromisso com o outro, passando pela revisão das práticas de gestão até os micros espaços de atuação profissionais nos quais saberes, poderes e relações interpessoais se fazem presentes. Dessa forma, a humanização só poderá ser compreendida a partir de sua temática complexa que permeia o fazer dos distintos sujeitos. ${ }^{20}$

Nesse sentido, percebeu-se por meio dos discursos dos estagiários que as relações constituídas pela experiência do estágio do Permanecer SUS tiveram uma contribuição marcante para o desenvolvimento da capacidade de se relacionar com outras pessoas e colaboraram para a desmistificação do conceito imediatista que caracteriza as relações de trabalho na saúde.

O programa me ajudou a conseguir ouvir, conversar com as pessoas [...]. O programa também me ajudou a ter uma relação com os colegas de estágio. (Estudante de Enfermagem)

É muito benéfico [sobre o Permanecer SUS] porque a gente aprende a lidar com as relações, a lidar um com o outro mesmo [...]. (Estudante do Bacharelado Interdisciplinar em Saúde)

Como um instrumento para facilitar o desenvolvimento das relações interpessoais, os estudantes reconhecem que o acolhimento pode ser utilizado de forma prioritária no Permanecer SUS.

0 processo de acolhimento no atendimento nos serviços de saúde implica em transformação do próprio modo como se concebe aquele que usufrui do serviço. De objeto passivo ao sujeito, de necessitado de atos de caridade àquele que exerce o direito de ser utente de um serviço que garanta ações técnica, política e eticamente seguras, prestadas por trabalhadores responsáveis. Essa transformação só ocorre mediante o relacionamento entre usuário e profissional. ${ }^{20}$

Para o desenvolvimento do acolhimento, a escuta qualificada é estimulada nesse campo, que deve ser realizada sem interferências e com total disponibilidade para ouvir o outro e suas necessidades. É importante conceituar a escuta qualificada como aquela que “mantém o vínculo com o paciente [...] permitindo à pessoa expressar-se e narrar sua 


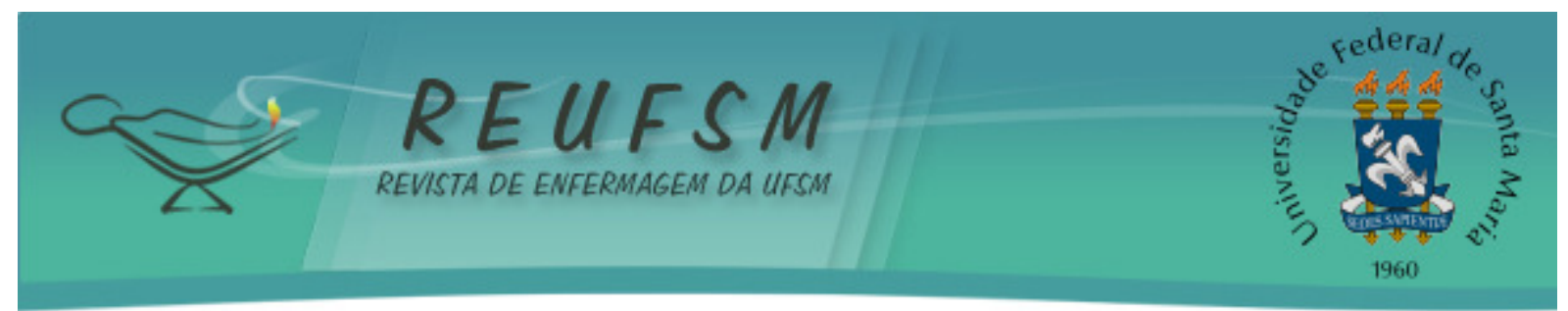

história de vida pessoal e familiar, formulando reflexões sobre seu atual estágio e desenvolvimento pessoal". ${ }^{21: 38}$

Além disso, alguns estudantes também relataram que o fato de estarem inseridos em equipes multidisciplinares e/ou interdisciplinares contribuiu para estimular a capacidade de comunicação entre seus pares e melhorar a relação com os usuários, pois, o tratamento com o paciente deve estar em harmonia com o trabalho da equipe de profissionais, facilitando a comunicação e a troca de informações.

Porque participar do Permanecer SUS me deu a compreensão de como chegar na pessoa, como falar, de se relacionar, entende? Ter uma relação interdisciplinar com as outras áreas, já que tem diversos cursos envolvidos, e aí a gente acaba conversando e tendo uma visão mais integral do usuário. (Estudante do Bacharelado Interdisciplinar em Saúde)

Por outro lado, apesar de contribuir para facilitar a comunicação, foi ressaltado por um estudante entrevistado, que as relações entre seus colegas estagiários e entre outros profissionais veteranos da unidade, sofriam impactos nas atividades desenvolvidas, devido, talvez à percepção errônea da realidade e das diferenças culturais:

Tinham alguns profissionais que não ajudavam, que viam a gente como um empecilho [...] tentavam tirar a gente da sala no momento do nosso atendimento, por exemplo, dizia que a gente não tinha função daquilo, que a gente estava atrapalhando o atendimento. (Estudante de Medicina)

A partir desse cenário é possível inferir que os estudantes consideram que o Permanecer SUS contribui na ampliação das relações e na reconstrução de referenciais que viabilizam a valorização das relações de trabalho, influenciando diretamente na prática do cuidar.

Assim, fica evidente que um dos impactos do estágio foi o desenvolvimento da capacidade de se comunicar entre seus pares, o que influencia diretamente na prática de cuidar, reconstruindo a valorização das relações como mecanismo de percepção do seu próprio perfil e dos demais envolvidos no processo.

\section{Clínica Ampliada (Humanização e Acolhimento)}

A clínica ampliada pode ser compreendida como um compromisso efetivo com os usuários de serviços de saúde, que passa a ser analisado de modo singular, numa relação na qual o profissional de saúde assume responsabilidade sobre os usuários dos serviços de saúde e reconhece os seus limites profissionais, buscando outros sujeitos, detentores de outros saberes, para conjuntamente executarem ações resolutivas e éticas. ${ }^{9}$

Nesse cenário, a humanização surge como uma forma de se valorizar os aspectos subjetivos, sociais e culturais do indivíduo. Desse modo, mostra-se como um exímio instrumento na melhoria da relação entre o profissional de saúde e o paciente. Ressalta-se que a prática da humanização requer a utilização de uma gama de tecnologias leves, como o acolhimento, por exemplo. ${ }^{22}$

0 acolhimento implica no estabelecimento de relações de aproximação de modo humanizado, na perspectiva do desenvolvimento da autonomia, e não pode ser encarado 


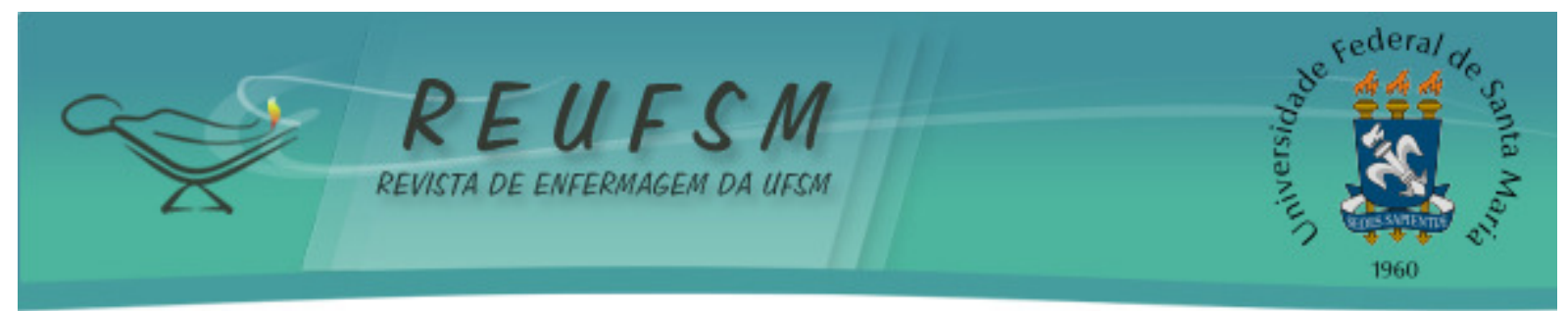

como responsabilidade exclusiva dos profissionais de saúde, pois é influenciado por fatores políticos, econômicos, sociais e históricos. ${ }^{9}$

Os discursos dos estagiários entrevistados demonstram a efetivação do acolhimento e da clínica ampliada no desenvolvimento das práticas do programa Permanecer SUS:

A gente realizava basicamente ações de acolhimento [...] ao mesmo tempo que a gente atendia os usuários atendia os seus familiares. (Estudante de Psicologia)

Percebe-se nos relatos que a clínica ampliada e o acolhimento facilitam a relação de respeito e a escuta mútua entre os estudantes e usuários. Além disso, pode propiciar grandes transformações nas práticas em saúde.

Ter sensibilidade para a escuta e o diálogo, mantendo relações éticas e solidárias, envolve um aprendizado contínuo e vivencial, levando-se em conta, ainda, o predomínio de estruturas administrativas tradicionais, rígidas e burocratizadas. ${ }^{20}$

Assim, é necessário o investimento na mudança das práticas de trabalho dos profissionais de saúde, a fim de que seja estimulado o acolhimento ao usuário, por meio da escuta qualificada bem como o compromisso de resolver seu problema de saúde e que a criatividade seja posta a serviço do outro. ${ }^{23}$ Dessa forma, para que essas novas práticas possam ser capazes de superar práticas inócuas e que sejam investidas em mudanças para o benefício do usuário e incentivem a sua autonomia.

0 processo de autonomia e o empoderamento dos sujeitos tornam os usuários protagonistas de seus próprios atendimentos e valorizam suas subjetividades, sendo essas condições substanciais para a oferta do cuidado integral na relação profissional-paciente. Isso foi comprovado nos discursos dos estagiários ao explicarem o cotidiano de trabalho no Permanecer SUS:

$\mathrm{Na}$ emergência nós tentávamos desatar os nós, que estavam impedindo a evolução do atendimento. [...] Procurávamos saber o que fazer para ajudar o paciente, qual era a história clínica do paciente, de onde ele veio, quais os problemas que ele estava enfrentando lá, procurando saber por que ele ainda estava lá, por que seu problema ainda não tinha sido resolvido. (Estudante de Enfermagem)

Nós fazíamos com o que usuário conhecesse seu direito e fosse buscar por ele, para que fosse acolhido em todas as suas necessidades, desde a mais básica a mais complexa. (Estudante de Psicologia)

Com base nesses relatos, percebe-se que os estudantes compreendem a necessidade de escuta ampliada dos pacientes para um atendimento humanizado. Nesse sentido, ressalta-se a necessidade de mudanças de paradigmas e de ações dos profissionais de saúde.

Tais mudanças, a exemplo das desenvolvidas pelo Permanecer SUS, possibilitam a vivência na prática dos conhecimentos desenvolvidos na universidade, aliando, assim, ensino-serviço, podendo estimular o processo de transformação e reestruturando os paradigmas vigentes.

Contudo, é necessário o desenvolvimento de metodologias que sejam capazes de inserir os estudantes em situações que tenha a capacidade de tocá-los, afetá-los, 


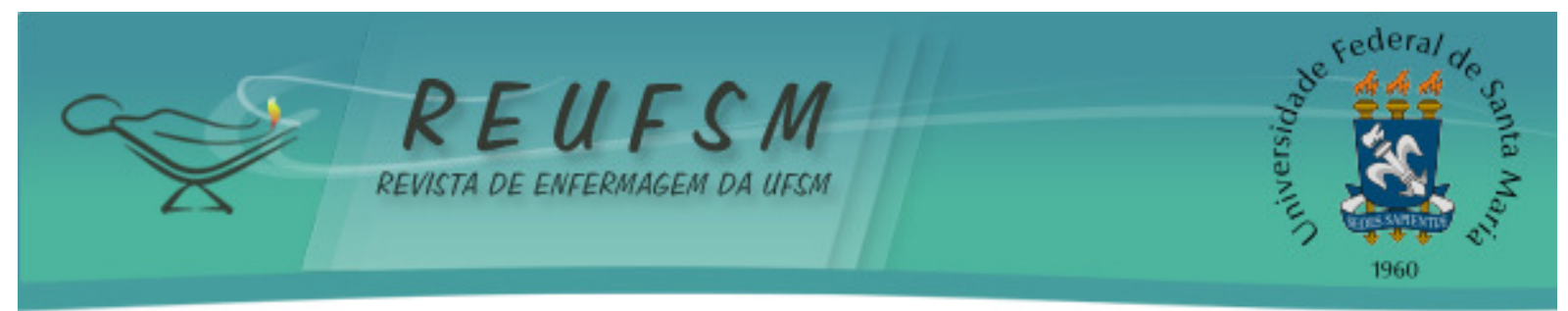

ressignificando o seu modo de ver e se portar diante do mundo, levando em consideração a individualidade dos sujeitos. Uma vez que não basta a inserção no serviço, é necessário a mudança do olhar. E esta acontece apenas num processo de inter-relação entre os indivíduos, no qual os saberes já adquiridos são reconfigurados e as práticas são recriadas. ${ }^{24-25}$

\section{CONCLUSÃO}

A partir dos resultados obtidos neste estudo, foi possível identificar a relevância que a inserção precoce no SUS propiciou ao desenvolvimento da escuta qualificada, uma maior habilidade no trabalho em equipe, e a criação de rede como dispositivos de fortalecimento da capacidade de resposta às demandas dos usuários.

A reflexão sobre como as relações interpessoais interferem e contribuem no desenvolvimento de ações, no desenvolvimento da autonomia e na corresponsabilidade também estiveram presentes nos discursos dos estagiários, sendo apontados como um diferencial possibilitado pelo estágio.

Entretanto, também foi destacado que um dos obstáculos encontradas nesse processo refere-se ao distanciamento entre alguns profissionais de saúde e estagiários, proporcionando, na maioria das vezes, dificuldade no acolhimento dos usuários.

Porém, mesmo diante das adversidades em trabalhar em equipe, houve capacidade de compreensão dos estagiários sobre o fator ambiência, assim como uma ampliação da percepção da própria autonomia e a criação de novos dispositivos de atuação frente aos serviços e profissionais. De tal forma que ações antes descontínuas e desarticuladas passaram a ser ferramentas de mudanças significativas e atuantes frente ao serviço.

O desenvolvimento da percepção, da consciência, da autocrítica e dos fatores condicionantes que influenciam no desenvolvimento das ações e serviços caracterizam a reflexão crítica dos sujeitos sobre como seu processo de trabalho e aprendizagem exerce papel fundamental no alargamento de suas práticas cotidianas.

Assim, o programa Permanecer SUS, utilizando-se da tecnologia leve - a escuta qualificada a ferramenta de humanização do atendimento e serviços de saúde proporcionou aos seus estagiários uma contribuição positiva para o bom desempenho de suas atividades quando profissionais.

Dessa maneira, conclui-se que o estágio do Permanecer SUS contribui tanto na ampliação do olhar frente ao usuário, profissional e serviço, quanto no tratamento ofertado pelo profissional aos usuários, oferecendo-lhes um atendimento integral e uma visão mais humana e acolhedora diante das dificuldades e burocracias enfrentadas no Sistema de Saúde.

\section{REFERÊNCIAS}

1. Dias HS, Lima LD, Teixeira M. A trajetória da política de reorientação da formação profissional em saúde no SUS. Ciênc Saúde Coletiva. 2013;18(6):1613-24.

2. Almeida Filho N. Reconhecer Flexner: inquérito sobre a produção de mitos na educação médica no Brasil contemporâneo. Cad Saúde Pública. 2010;26(12):2234-49

3. Carvalho YM, Ceccim RB. Formação e Educação em saúde. In: Campos GWS, Bonfim JRA, Minayo MCS, Akerman M, Drummond-Júnior M, Carvalho YM, organizadores. Tratado de Saúde Coletiva. Rio de Janeiro: Hucitec; 2012. p.137-70.

4. Santos Filho SB. Perspectivas da avaliação na Política Nacional de Humanização em Saúde: aspectos conceituais e metodológicos. Ciênc Saúde Coletiva. 2007;12(4):999-1010. 


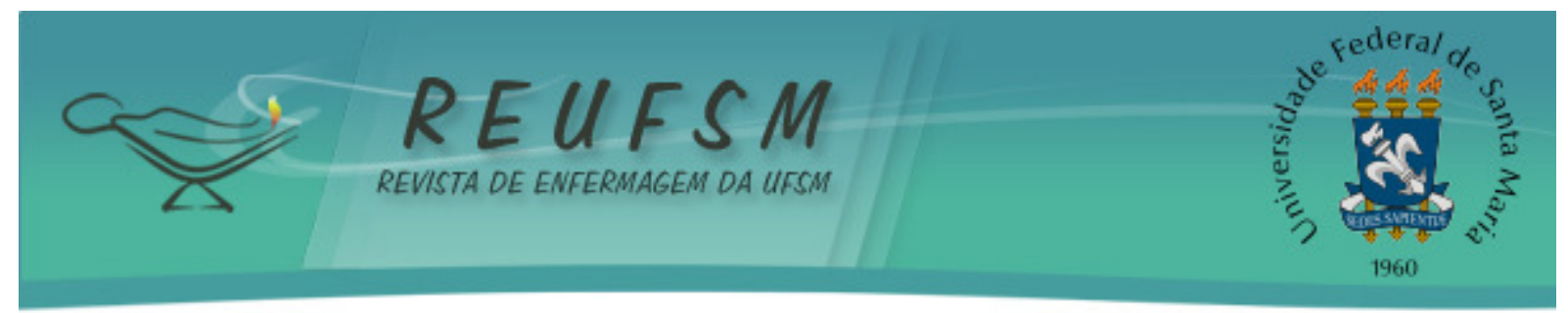

5. Deslandes SF, Mitre RMA. Processo comunicativo e humanização em saúde. Interface (Botucatu). 2009;13(1):641-9.

6. Hennigton EA. Gestão dos processos de trabalho e humanização em saúde: reflexões a partir da ergologia. Rev Saúde Pública. 2008;42(3):555-61.

7. Chernicharo IM, Silva FD, Ferreira MA. Humanização no cuidado de enfermagem nas concepções de profissionais de enfermagem. Esc Anna Nery. 2011;15(4):686-93.

8. Torres QSN. Estágio de vivência no SUS de Alagoas: contribuições para a formação do profissional da saúde [monografia]. Maceió: Universidade Federal de Alagoas, Faculdade de Medicina; 2008. 38 p.

9. Brasil. Ministério da Saúde. Núcleo Técnico da Política nacional de humanização. HumanizaSUS: política nacional de humanização: documento base para gestores e trabalhadores do SUS. Brasília (DF): Ministério da Saúde; 2004.

10. Rodrigues MLR. Caminhos da transdisciplinaridade: fugindo às injunções lineares. Serv Soc Soc. 2000;64(1):124-34.

11. DeVault ML, McCoy L. Institutional ethnography, using interviews to investigate ruling relations. In: Gubrium FJ, Holteins JA, organizers. Handbook of interview research: context and method. Thousand Oaks/London: Sage; 2002. p. 751-76.

12. Orlandi EP. Análise de discurso: princípios e procedimentos. Campinas, SP: Pontes Editora; 2013.

13. Brasil. Ministério da Saúde. Conselho Nacional de Saúde. Resolução CNS n 466, de 12 de dezembro de 2012. Diretrizes e normas regulamentadoras de pesquisa envolvendo seres humanos. Brasília (DF); 2012.

14. Peduzzi M. Equipe multiprofissional de saúde: conceito e tipologia. Rev Saúde Pública. 2001; 35 (1):103-9.

15. Velloso C. Equipe multiprofissional de saúde. Rev E F. 2005;17(1):23-6.

16. Machado MFAS, Monteiro EMLM, Queiroz DT, Vieira NFC, Barroso MGT. Integralidade, formação de saúde, educação em saúde e as propostas do SUS - uma revisão conceitual. Ciênc Saúde Coletiva. 2007;12(2):335-42.

17. Feuerwerker LCM, Sena RR. Interdisciplinaridade, trabalho multiprofissional e em equipe. Sinônimos? Como se relacionam e o que têm a ver com a nossa vida. Rev Olho mágico. 1998;5(18):1-6.

18. Meirelles MCP, Kantorski LP, Hypolito, AM. Reflexões sobre a interdisciplinaridade no processo de trabalho de centros de atenção psicossocial. Rev Enferm UFSM [Internet]. 2011 [acesso em 2014 abr 26];1(2):282-9. Disponível em: http://cascavel.ufsm.br/revistas/ojs2.2.2/index.php/reufsm/article/view/2551/1689.

19. Pedroza RLS. Relações interpessoais: abordagem psicológica. Brasília (DF): Ministério da Educação; 2006.

20. Casate JC, Côrrea AK. Humanização do atendimento em saúde: conhecimento veiculado na literatura brasileira de enfermagem. Rev Latinoam Enferm. 2005;13(1):105-11

21. Ceron M. Habilidades de Comunicação: abordagem centrada na pessoa. São Paulo: UNA-SUS, UNIFESP; 2010. 


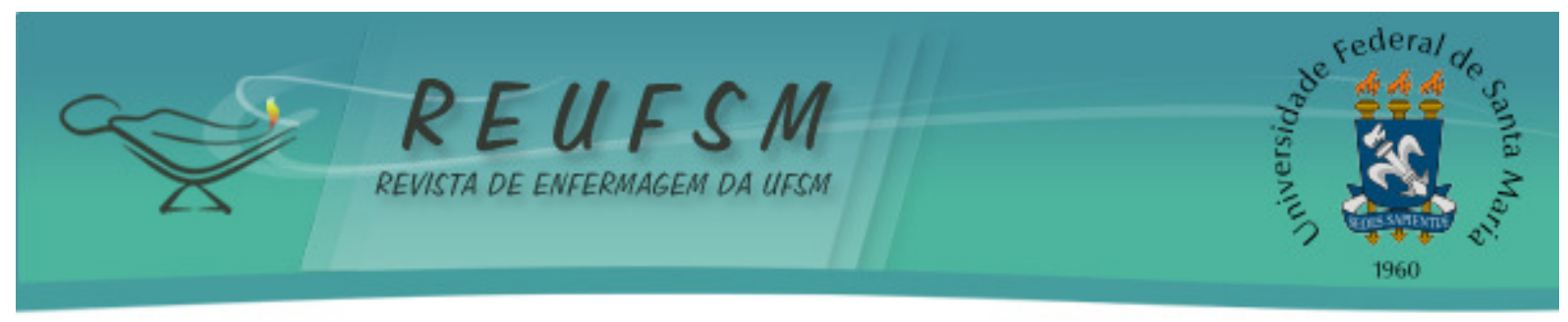

22. Goulart BNG, Chiari BM. Humanização das práticas do profissional de saúde: contribuições para reflexão. Ciênc Saúde Colet. 2010;15(1):255-68

23. Franco TB, Merhy EE. Programa de Saúde da Família (PSF): contradições de um programa destinado à mudança do modelo tecnoassistencial. In: Merhy EE, Magalhães Júnior HM, Rimoli J, Franco TB, Bueno WS, organizadores. O trabalho em saúde: olhando e experienciando o SUS no cotidiano. São Paulo: Hucitec; 2006. p.55-124.

24. Ceccim RB, Feuerwerker LCM. O quadrilátero da formação para a área da saúde: ensino, gestão, atenção e controle social. Physis. 2004;14(1):41-65.

25. Franco TB, Galavote HS. Em busca da clínica dos afetos. In: Franco TB, organizador. Semiótica, afecção \& cuidado em saúde. São Paulo: Hucitec, 2010. p.70-85.

Data de recebimento: 23/04/2014

Data de aceite: 03/08/2015

Contato do autor responsável: Wilton Nascimento Figueredo

Endereço postal: Universidade Federal da Bahia. Instituto de Humanidades, Artes e Ciências Milton Santos. PAF IV. Rua Barão de Jeremoabo, s/n - Térreo - Sala T11. Bairro: Ondina. Salvador, Bahia, Brasil. CEP: 40170-115

E-mail: enfer.willfigueredo@gmail.com 